\title{
AlfabeTIZAR/Ensinar HistóRIA No PEART
}

\author{
Regina Célia Alegro* \\ Maria das Graças Fernandes"
}

Resumo: Apresenta algumas considerações sobre a prática de alfabetização e ensino de História propostos no PEART

Unitermos: bóia-fria; educação popular; linguagem; ensino de história; Peart.

Através do espaço para debates e trocas de experiências criado pelo Laboratório de Ensino de História, estamos desenvolvendo um subprojeto voltado para a capacitação dos monitores de alfabetização do PEART, para o ensino de História e o acompanhamento do cotidano do processo de ensino-aprendizagem concretizado neste Projeto. No interior do projeto surgem algumas questốes que, acreditamos, na medida em que forem exploradas, podem contribuir para a reflexão acerca do ensino de História.

O PEART apresenta-se como um projeto de educação popular gestado na prática dos novos movimentos sociais, ou seja, aqueles que emergiram durante o regime militar, sobretudo durante o movimento de redemocratização do pais. Estes novos movimentos voltam-se para as bases perseguindo a possibilidade de autonomia, autogestão, cessação de privações de toda ordem, como condições para a liberdade e igualdade pressupostas na idéia de cidadania. (Covre, 1986)

\footnotetext{
Professora do Departamento de História - Universidade Estadual de Londrina Londrina/PR

" Professora do Departamento de Educação - Universidade Estadual de Londrina Londrina/PR
} 
ALEGRO, R \& FERNANDES, M. C. Alfabetizar/ensinar no PEART.

De fato, o popular relaciona-se a exclusão cultural, de consumo, de participação nas decisões, etc. Como afirma Montaño (1994:75) o popular extrapola, reúne e integra conceitos como classe trabalhadora, setor carenciado, entre outros. Nessa perspectiva, a educação popular pretendida no PEART volta-se tanto para as possibilidades não desenvolvidas como para as potencialidades transformadoras dos bóiafrias.

Os bóias-frias, na singularidade do modo como vivem, são a configuração da efemeridade que marca a nossa sociedade. Isto porque a vida para eles constitui-se de momentos determinados pela absoluta necessidade de sobrevivência. A politica econômica pós-64 trouxe a desagregação social, particularmente ao pequeno proprietário de terra, aos poucos substituído pelas máquinas enquanto perdia suas terras para os grandes latifundiários. Isto na velocidade permitida pela opção político-econômica respaldada no avanço tecnológico.

Nesse quadro é que aparece o bóia-fria como população sobrante, marginalizada, habitante de favelas, sujeita à fome, às doenças, à violência sob muitas formas. Enfim, uma população que, aparentemente - e só aparentemente-, não fará nenhuma diferença caso desapareça, embora represente uma parcela significativa da mão-deobra produtiva no meio nural.

Nessas condições os bóias-frias se submetem às variações do sistema agrícola, deslocando-se num etemo ir e vir, em busca de trabalho. Portanto, as relações que estabelecem têm traços de inconstância, do passageiro, são construídas dentro de uma transitoriedade característica de seu modo de viver itinerante.

A intinerância provoca dificuldades objetivas e subjetivas do ponto de vista da construção de relações afetivas, sociais, culturais e outras. Estar hoje aqui, daqui a alguns meses a centenas de quilômetros... As relações obrigatoriamente terão que se reconstituir com o novo gato, novos amigos, nova cidade...

Neste quadro toma-se primordial para o bóia-fria criar formas de comunicação e linguagens que permitam preservação individual e coletiva. Individual, na medida em que sua utilização garante o espaço necessário para a estruturação e a sistematização dessa linguagem 
ALEGRO, R \& FERNANDES, M. C. Alfabetizariensinar no PEART.

forçando o que ouve a buscar elementos que permitam a compreensão daquele que fala. Coletiva porque, estruturada e sistematizada, legitima um tipo de linguagem que caracteriza, na sua expressão, uma determinada população. A utilização desses códigos - gíria - pelo gnupo proporciona o cultivo de uma memória coletiva expressa oralmente.

A linguagem é um processo mnemônico e se relaciona com a capacidade de reter, reorganizar e passar uma informação adiante. Nesse sentido, é um instrumento do pensamento, um acervo de conhecimento $e$, ao mesmo tempo, memória coletiva. São as lembranças que permitem reconstituir o tempo da roça à luz da experiência na cidade. Era tempo de pobreza, da dureza, mas também tempo de fartura porque não havia fome, do respeito com os mais velhos, das festonas. Nestas lembranças, experiências, personagens e lugares perpetuam-se ao representarem parâmetros para a leitura do passado e do presente.

Nesse quadro é que podemos detectar a fala como elemento criador de sentimentos e da noção de pertencimento, pois ela faz a mediação na percepção das novas realidades constantemente propostas ao bóia-fria enquanto cria elementos de resistência ao processo de sedução desencadeada pela conviência com o gato, o padre, o sindicalista, o patrão. Perder o jeito de falar é a mesma coisa que perder o jeito de pensar sobre si mesmos e sobre o grupo ao qual pertencem.

A título de ilustração registramos aqui trechos de uma entrevista com um jovem bóia-fria. Ah, o trampo é cansativo embora a gente enrola também. O gato paga uma micharia. De vez em quando eu vou pra tirar uns troco (...) a gente tem vergonha, né. Sabe, o bóia-fria é desvalorizado; estou nisso por bico, as minas não gosta de quem trampa de boião. (Peart, 1993).

O modo de falar debochado, irônico, revela uma elaboração da concretude em que vivem, da rede de relações que estabelecem, dos mecanismos de que se utilizam para compreender as mensagens recebidas e decodificá-las nos seus diversos âmbitos. Nas entrelinhas, a ironia e o deboche não são mais do que um jeito particular de enfrentar a miséria, encarar e rir da vida através de códigos que lhes permitem organizar as próprias experiências sem não entregar os pontos. 
ALEGRO, R \& FERNANDES, M. C. Alfabetizar/ensinar no PEART.

Como afirma Colosso (1990) existe um aprendizado especifico na adaptação à cidade e, é claro, o bóia-fria percebe as contradições em que vive. Porém, este aprendizado é marcado pela estreiteza do discurso dicotômico pobre-rico, ignorante-inteligente, ... de forma que o bóia-fria raramente chega a compreender as contradições que determinam sua existência. Submetido a contingência de sobreviver, ou seja, impossibilitado de decidir sobre sua vida, vive-a como uma factividade evidente e compulsória a ponto de não reconhecer como a realidade é construída. Ou seja, embora sua vasta experiência de vida, o seu cotidiano não oferece instrumentos para a compreensão de que linguagem e poder estão intimamente ligados e são parte de um único processo de cooptação e de convencimento de que tudo o que é bom e é valorizado não está neles, não faz parte do seu universo, mas está no outro e pertence ao universo do outro.

Gherre (1987:34) explicita que as regras que governam a produção apropriada dos atos de linguagem levam em conta as relações sociais entre o ouvinte e o falante. E permite-nos constatar que uma variedade lingiüistica 'vale' o que 'valem' na sociedade os seus falantes. Logo, os que se utilizam de palavras como as citadas acima são a parte sobrante da sociedade, excluída dos processos de socialização usados pelas camadas mais favorecidas.

No interior deste quadro é que iniciamos a busca de uma proposta de ensino de História no PEART. Encontramos as pistas seguintes.

Castoriadis (1982:379) concebe a linguagem como um pressusposto lógico da percepção plena do sujeito. Dizer, pois que um sujeito tem acesso a um mundo (...) é dizer (...) que ele é em e por tal linguagem [particular].

Embora essa percepção do mundo não seja individual ou essencialmente independente da instituição social do individuo, da coisa, do mundo, nos alerta para o fato de que o sujeito não é redutivel à sua instituição social-histórica. Esta é, segundo Castoriadis, condição para a efetivação da percepção do mundo pelo sujeito.

As questões propostas por Castoriadis nos permitem a reflexão acerca da necessidade do reconhecimento da originalidade $\mathrm{e}$ criatividade do bóia-fria como sujeito e não uma coisa no mundo. 
ALEGRO, R \& FERNANDES, M. C. Alfabetizar/ensinar no PEART.

Procuramos então associar estes pressupostos a uma proposta didática para alfabetização de bóias-frias, a partir das pesquisas de Emilia Ferreiro acerca das concepções dos alunos durante o processo de aquisição da escrita e da leitura, e, de Paulo Freire, quando propõe a leitura e escrita da realidade.

Castoriadis afirma que falar é o fazer dos homens na linguagem. (1982:391) É do espaço do fazer (que prevalece no contexto do aluno) que parte o processo de alfabetização dos bóias-frias para uma forma mais ampla de falar, ou seja, a construção de um campo conceitual. Nesse caso o conhecimento é entendido como a organização, segundo a estruturação do pensamento do sujeito que aprende, dos conceitos aprendidos tanto na escola como na experiência cotidiana. (Grossi,1989:45)

Consideramos que os conteúdos curriculares em História e a forma como geralmente são ministrados transformam os alunos em armazenadores de conteúdos que não têm relação ou significado para suas vidas. Trata-se, então, de garantir o acesso ao patrimônio cultural e científico da humanidade e a preparação para a produção de mais conhecimentos, desconsiderando a aprendizagem como um fim em si mesma. (Grossi, 1989: 24)

O conhecimento não se efetiva de fora para dentro do individuo, mas pressupõe uma elaboração intema. Não se trata de transmitir coteúdos, mas através da aprendizagem de conteúdos, permitir o desenvolvimento dos mecanismos de elaboraçăo do conhecimento. (Grossi, 1989:51)

Este é um ponto importante: o desenvolvimento do pensamento conceitual pressupõe, além das experiências cotidianas, a aprendizagem no interior das disciplinas, que ao manterem a sua especificidade, oferecem materiais e problemas para o estabelecimento das relações que determinam os conceitos $e$ as suas representações.

Tomemos um exemplo: em várias turmas do PEART podemos constatar que embora assistam jornais televisivos diariamente, alguns alunos não têm noção de que exista algum espaço para além daquele que freqüentam. Em Sertanópolis, por exemplo, uma bóia-fria, com menos de 30 anos, ficou maravilhada e temerosa ao descobrir 
ALEGRO, R \& FERNANDES, M. C. Alfabetizar/ensinar no PEART.

(elaborar) que existe espaço para além dos limites da sua cidade (que ela nunca havia ultrapassado). Outros alunos achavam que São Paulo era a capital do Brasil e não sabiam distinguir o Estado da Capital de São Paulo, etc.

Pode-se perceber como palavras e experiências estão sendo apresentados aos bóias-frias com a superficialidade e a rotatividade carcaterísticos dos nossos dias, especialmente através da televisão, sem que se lhes ofereça a possibilidade e os elementos necessários para o estabelecimento de relações que permitem a construção de um conceito, de um feixe de remissóes a partir e em tomo do termo, como diria Castoriadis (1982:390)

Diante deste quadro, cientes de que controlar a memória é exercicio de poder e de que o interrogar-se permite o refazer da atividade prática, a assessoria implementou um trabalho de análise das produções escritas dos alunos e a partir delas elaboramos cursos para os monitores onde provocamos discussões que conduzem a tomada de decisões sobre as mais diferentes formas de conduta pedagógica na sala de aula. Nosso objetivo é desvelar o sentido particular de palavras e expressões como zóião, as minas não gosta de quem trampa de boião, tirar uns troco, as festonas de antigamente, e outras, e tomá-las ponto de partida para a compreensão e dominio do padrão de linguagem socialmente aceito. $\mathrm{E}$, nesse processo, de desvendar a linguagem que expressa a memória, apontar ao alfabetizando os caminhos da história.

$O$ ensino de História no processo de alfabetização se efetiva a partir do interesse dos alunos. E interesse não falta. Um exemplo: Dona Geraldina tinha um vizinho que foi para o Japão. Isto a levou a querer saber porque aqui é dia quando no Japão é noite. $\mathrm{O}$ interesse passou a ser da turma e aí aconteceu algo inusitado: entre as primeiras palavras que a turma escreveu estavam Japão, Terra, dia, noite, lua, ano, nascimento, etc. $E$ o monitor, enquanto apresentava o alfabeto aos alunos, pode desenvolver junto com a turma (com idade variando entre 44 e 77 anos) entre outras atividades, confecção de globo terrestre, maquete do sistema solar, dramatizaçōes, produção de texto coletivo-os alunos verbalizavam e o monitor registrava o texto no quadro negro-, 
ALEGRO, R \& FERNANDES, M. C. Alfabetizar/ensinar no PEART.

experiências para discussão dos movimentos da Terra, observação e registro das fases da lua, etc.

O monitor determinou como objetivo geral para estas atividades a elaboração, pelos os alunos, da noção, de tempo natural. Quando pôde fazer a síntese, discutindo com eles o que seria tempo natural iniciou atividades e discussões sobre o tempo histórico. Esse tema foi introduzido com o mapeamento da trajetória da familias dos alunos (nenhum é originário de Londrina), a verificação de como as diferentes gerações das familias viveram ou conceberam questões como o papel da mulher, casamento, migração, trabalho, alimentação, a escola, etc. Novamente o inusitado aconteceu: a turma reivindicou uma visita ao Museu Pe. Carlos Weiss.

As possibilidades temáticas foram se alargando e conteúdos curriculares como o descobrimento do Brasil, escravidão indigena e negra, etc. estão sendo abordados durante o processo de alfabetização, sem temor do prazer da descoberta.

Este é, pois, o universo de trabalho do PEART: a subjetividade, a identidade, a vivificação da memória, através da valorização da variedade lingüistica utilizada pelos bólas-frias. Assim, mais que escolher e adotar um método de ensino, no PEART existe a preocupação em descobrir formas de privilegiar o desenvolvimento do raciocínio lógico, de habilidades mentais necessárias ao uso da linguagem e consequentemente, escrita. $E$, de atividades que promovam a transposição dos novos conhecimentos adquiridos para a vida cotidiana. Podemos afirmar que ao não optar por um método de ensino em especial, as pessoas envolvidas nesse processo - monitores e alunos - têm uma oportunidade impar de re-inventar seus próprios métodos, suas formas de aprender e de ensinar e assim reconhecer-se como personagens concretos da história vivida.

Isto é garantir às linguagens especiais, ou seja, de cada segmento que constitui o PEART, a função que thes é inerente: a socialização. Além disso, estamos contribuindo na aquisição e organização de códigos de linguagem que auxiliem no acúmulo da experiências e práticas sociais e que se configurem como instrumentos de luta por espaços políticos maiores e mais significativos. 
ALEGRO, R \& FERNANDES, M. C. Alfabetizariensinar no PEART.

Assumimos um duplo risco ao não definir antecipadamente um método e ao optar por permitir que esse método se construa simultaneamente à construção do próprio Projeto. Essa decisão, porém, baseou-se na riquíssima heterogeneidade, que é o elemento constitutivo mais significativo do PEART. E onde as idéias, os desejos, as posições políticas, as crenças, as experiências eclodem e proliferam determinando um ritmo próprio para o caminhar das atividades e para os resultados que ele alcança em cada região.

Corremos também outros riscos no PEART. Por exemplo, o representado por uma concepção de educação popular onde o altemativo, baseia-se primeiro na visão romântica de que basta ser militante e fazer um discurso revolucionário para preparar os excluídos ao embate com a classe dominante. $\mathrm{Ou}$, o preconceito contra o conhecimento acadêmico/científico julgando-o elitizado, agressivo e inadequado ao trabalho com as classes marginalizadas, levando a atitude comum de recusar toda e qualquer iniciativa de discutir novos conhecimentos fundados em teorias diferentes das latentes na ação do grupo.

Ou ainda, a desconsideração de que a consciềncia não se dá, nem se transmite, mas é fruto de condições materiais, sociais, econômicas e políticas e por isso mesmo, não é propriedade deste ou daquele grupo em particular. Mais ainda, incoerência com objetivos de transformação social, por considerar como resgate da cidadania apenas a obtenção de patamares mínimos de subsistência. A realidade é clara e indiscutível: subsistir não é ser cidadão.

Observa-se que a pobreza é mantida também mediante ações que negam a dinâmica contraditória da sociedade. Um trabalho que tenha por finalidade o acesso e inclusão das camadas sociais marginalizadas aos bens culturais, riqueza produzida pela sociedade - e não apenas por individuos-, não pode ter como conhecimento fundante, apenas o conhecimento gerado no grupo. Qualquer projeto de educação que pretenda contribuir para a transformação social, tem que considerar o conhecimento como instrumento privilegiado para criar o homem audacioso, que expõe suas idéias; o homem não dirigido, não conformado, nem manipulado; que discute e compete - também - 
ALEGRO, R \& FERNANDES, M. C. Alfabetizar'ensinar no PEART.

porque produz o conhecimento necessário para sua autonomia, e que busca a completude da sua condição humana.

Finalmente, pensar a educação de adultos na perspectiva da cultura popular, como quer o PEART, é acrescentar algo além do ato de ensinar a ler e escrever. $O$ próprio conceito de educação, engloba ações diversas, mais ou menos elaboradas pelos sujeitos e que se constróem nas suas relações cotidianas.

Envolver-se nas atividades de dança, cantigas de roda, dramatizações, conversas e outras é reconstruir a memória a partir das relações manifestas pelo grupo. Estas manifestações estão repletas do conhecimento que se acumula através das gerações e faz parte das comunidades (como objeto particular) que o utilizam de acordo com as suas necessidades, ou seja, esse conhecimento é o instrumento na busca pela sobrevivência. Porém, é necessário não acreditar que sobreviver apenas, seja a aspiração dos milhões de pessoas que estão hoje à margem da sociedade. Isto representa um nivel de aspiração baixíssimo e não significa em absoluto que alguém que apenas sobreviva, chegue a ser cidadão, algum dia.

Consideramos a alfabetização, como capacidade de reinterpretação de códigos escritos, mais um instrumento, que, unido àqueles que já fazem parte da forma de vida dos jovens e adultos analfabetos, irão se constituir numa possibilidade a mais de compreender a realidade em que vivem, atuam e produzem. Que irão provocar desafios e inquietações diante de situações como: curar-se pela medicina caseira por opção ou pela exclusão do sistema nacional de saúde, embora os trabalhadores paguem por estes serviços antecipadamente? Aprender receitas de bife de cascas de banana, farinha de caroços e pernil de talos de jaca assado, enquanto outros - quem e por quê? - comem a polpa?

Enfim, são muitos os instrumentos e argumentos do sistema capitalista, para convencer os trabalhadores a permanecerem no seu devido lugar, um lugar de ignorância e servidão, a convencê-los da sua incapacidade de ir além, de superar-se a si mesmos e às barreiras que os dominam e imobilizam. A nosso ver, alfabetizar, para decodificar letras e sílabas ou para assinar o nome é um deles 
ALEGRO, R \& FERNANDES, M. C. Alfabetizar/ensinar no PEART.

Um projeto de educação que pretenda atuar para provocar mudanças, tem necessariamente que armar-se de instrumentos produzidos pela ciência e pela tecnologia, além daqueles que fazem parte do cotidiano do grupo, visíveis nas suas manifestações culturais Instrumentos estes que se configuram no professor (monitor) preparado para trabalhar com eles; nos grupos de assessoria e em qualquer outro elemento que signifíque e possibilite a troca de saberes e aprendizagem reciprocas, de forma que o conhecimento produzido nessa interação, seja a mais legítima forma de construção do conhecimento produzido pela sociedade. Isto porque o conhecimento não é propriedade particular justamente porque se produz nas e das relações de trabalho entre os homens, portanto, é universa!. E esta universalidade é que o caracteriza como possibilidade de que os grupos marginalizados - como os bóias frias, possam aprender a ler e escrever as palavras, mas também e principalmente, ler, escrever e compreender a política, a economia, ... a tecnologia que garante melhor aproveitamento do solo, da produção de alimentos, da criação, da distribuição e ocupação da terra, etc.

Nesse sentido, perseguimos uma proposta de ensino de história marcada pelo projeto de elucidação das formas passadas da existência da humanidade que só adquire seu sentido pleno como momento do projeto de elucidação da nossa existência, por sua vez inseparável do nosso fazer atual. (Castoriadis, 1982;197)

\section{Referências Bibliográficas}

CASTORIADIS, Comelius. A Instituição Imaginária da Sociedade. Rio de Janeiro: Paz e Terra, 1982.

COLOSSO, Leonardo. Bóia-fria da Silva. Dissertação de Mestrado. Assis: Unesp, 1990. 
ALEGRO, R \& FERNANDES, M. C. Alfabetizar/ensinar no PEART.

COVRE, Maria de L. M. (org.) A cidadania que não temos. São Paulo: Brasiliense, 1986

CPT. Os bóias-frias no Paraná. CPT : Londrina: mimeo. 1991

GROSSI, Esther P. Alfabetização em novas bases. Porto Alegre: Kuarup, 1989

GHERRE, Maurízzio. Linguagem, Escrita e Poder. São Paulo:

Martins Fontes, 1985

FREIRE, Paulo; MACEDO, Donaldo. Leitura da palowra - leitura do mundo. Rio de Janeiro: Paz e Terra, 1990.

MONTAÑO, Carlos E. "Políticas Sociais para quem? Conceituação do popular". Revista Serviço Social \& Sociedade. São Paulo: Cortez. ${ }^{\circ} 45$, ano XIV, ago. 1994. 